\title{
Visual Analogy as a Cognitive Strategy in the Design Process: Expert Versus Novice Performance
}

\author{
Hernan Casakin
}

This study investigated the use of analogy in architectural design. Its main purpose was to provide some understanding of the way experts and novices apply visual analogical thinking to generate satisfactory solutions during the design process. A series of controlled experiments were conducted in order to examine how this cognitive strategy contributed to the enhancement of design problem solving in each group of subjects. Students and architects were asked to solve a set of non-routine design problems stimulated by exposure to visual displays, and were given explicit instructions to use analogy.

Results showed that both novices and experts were able to reason by visual analogy and use deep analogs. It was found that experts identified and retrieved analogs from between-domain displays. Novices, however, identified a large number of between-domain displays, but retrieved analogs from between-domain and within-domain displays in the same measure. Novices, in contrast to experts, did not add constraints to the design problem, but produced a large number of solutions. These findings have important implications on design education.

W hat are the differences between expert and novice performance in the domain of design? How can we help designers solve nonroutine design problems while using familiar knowledge structures? The production of an unlimited number of unexpected solutions that are significantly different from earlier designs is a characteristic of non-routine design. Design problems are described as major examples of non-routine problems (Gero and Maher 1993). In design, visual analogy is a powerful problem solving strategy that can help explain new and non-routine problems in terms of familiar ones. Although there is some evidence that problem solvers have difficulty in making spontaneous use of this strategy, references concerning the use of analogy are mostly anecdotal. Moreover, differences in expertise as regards the use of visual analogy in design have rarely been reported.

The main goal of this study is to provide empirical evidence regarding differences and similarities in the performance of expert and novice designers whose reasoning process involves visual analogy. Qualitative and quantitative results in the use of visual analogy during the design process are presented following a brief literature review. 


\section{Reasoning by analogy: source and target}

Thinking in terms of analogy involves the transfer of prior knowledge from a familiar situation (named the source), to a situation that should be elucidated (named the target) (Gentner 1983; Novick 1988; Vosniadou 1989). The identification and retrieval of a similarity between potential relations in the target, and known relations in the source enables to understand the new situation on the basis of a familiar situation.

Gentner's (1983) Structure-Mapping Theory supports the view that an analogy can be characterized as the application of a system of major structural relations from a source, to the problem to be solved. Another, more pragmatic theory proposed by Gick and Holyoak (1980), as well as by Holyoak (1990), maintains that analogical mapping is triggered when a source analog presents a solution procedure that seems to be more efficient than a rule of inference. The selection of a source analog is a consequence of rule activity directed at the way to solve the target problem. In this theory, structural principles are considered as secondary, and mapping is directed by the importance of the predicates as regards the goals at hand. Thus, the goals of the target largely control the mapping process.

\subsection{Component Processes in Analogical Reasoning}

The main processes of analogical reasoning consist of: (i) identification and retrieval; (ii) mapping and transference. These are described as follows:

i) Identification and retrieval: Subjects identify and represent the target situation according to various features that may hold abstract solution principles. These features provide memory retrieval hints, which are useful to access significant knowledge about known situations. A number of experiments have been carried out to study the retrieval process through the hint/no-hint paradigm. These included the provision of sources containing instructions, key words, or visual hints such as diagrams harboring a solution principle similar to the target problem. Gick and Holyoak (1980) argued that when subjects were not explicitly told to relate a visual source to the problem, they tended to fail in the retrieval and application of analogical principles. Weisberg and Alba (1982) found that the mechanical utilization of a hint should not be presupposed. They claimed that hints could be of assistance only when subjects have sufficient expertise and knowledge to establish a relationship between then and the problem at hand.

ii) Mapping, and transfer: When a potential source analog is retrieved, subjects establish correspondences between objects and between relations among objects, in the source and the target situations (e.g., Novick and Holyoak 1991; Sternberg and Ketron 1982; Vosniadou and Ortony 1989), and strive to see how an analogical principle can be transferred. This process is considered to be of critical importance for the analogical reasoning process. Successful mapping increases the possibility 
of a successful transference of a solution principle from source to target increases.

\subsection{Surface analogies and structural analogies}

According to theoreticians like Gentner (1983), Rips (1989), Smith (1990) and Vosniadou (1989), an analogy can be categorized into surface analogy and deep (structural) analogy. Surface analogies relate to easily accessible or superficial concepts of object properties. Researchers such as Gentner (1989), and Keane (1988) argued that although these types of analogies are easy to create, under normal circumstances they could not guarantee the transfer of structural relations between source and target. Structural analogies, on the other hand, involve a system of higher order relations that are based on deep properties of a familiar situation. These types of analogies have a strong influence on the quality of the solution.

\subsection{Within-domain, and between-domain analogies}

An analogy can be established between two different domains, each of which embrace dissimilar knowledge, but with a common shared correlation based on similar structural aspects. This type of analogy is known as 'between-domain', where the source, and the target problem belong to different and distant domains. In cases in which source and target are embedded in the same or very close domain, the analogy is called 'within-domain'. The level of difficulty in accessing and transferring an analogy is largely dependent on how remote or close the distance between target and source is (Johnson-Laird 1989). The use of withindomain and between-domain visual displays may have an influence on the quality of an analogy. Between-domain analogies are based on structural commonalties, and are therefore more difficult to access. However, when accessed, they are supposed to lead to a successful analogy (Vosniadou 1989). Dejong (1989) claimed that within-domain analogies are mainly based on surface similarities, and therefore are easier to establish. Vosniadou (1989) claimed that successful analogical reasoning can be employed between any two items that belong to the same domain provided it involves transferring an explanatory structure from one item to the other. The use of within-domain and between-domain visual displays will be further studied within the context of expertise in design problem solving.

\subsection{Visual thinking and visual analogy in design}

Most researches in cognitive science have focused on the domains of vision and visual perception, (e.g., Beveride and Parkins 1987; Gick and Holyoak 1983) however studies on visual analogy have rarely received attention.

Visual thinking and visual analogy have always been seen as important aids in design problem solving (e.g., Goldschmidt 1995). In design tasks, where visual thinking is largely employed, designers are frequently assisted by visual stimuli such as visual displays. The designers' reference to visual displays, explains why visual analogy is an appropriate strategy for enhancing design problem solving (Goldschmidt 1994; 1995; 1999). 
Beyond anecdotal examples illustrated in the design literature, recent works have provided empirical evidence of the role of visual analogy in design (e.g., Verstijnen et al 1999; Casakin and Goldschmidt 1999; 2000; and Casakin 2002). These empirical studies indicated that the use of visual analogy improves the quality of design solutions. In most cases, instructions to use analogy were considered to be a critical factor of success. Failure or success in the use of analogy was assessed through the quality of the design solutions obtained. However, aspects related to the use of visual analogy during the design process remained unexplored.

\section{Expertise and the role of knowledge}

Experience and knowledge in a specific domain are basic requirements to develop expertise. Knowledge assists in finding solutions to problems, which gradually become familiar (Dominowski 1995). In reference to unconventional use of knowledge, Akin (1990) stressed the relevant roles of productive thinking in creative problem solving tasks, such as design. Like Wertheimer (1959/1982), he further differentiated reproductive from productive uses of knowledge. While the former implies a new problem situation that can be solved by recalling and using prior knowledge, the latter concerns a change in the perceived focus of the new problem at hand. Researchers like Glaser (1989), Medin and Ross (1990), or Newell and Simon (1972) claimed that distinctions in proficiency between novices and experts depend on the nature of problem representation. Experts, who have more developed and integrated knowledge structures, are likely to concentrate on relevant aspects; on the other hand, novices who have a lower level of developed knowledge, tend to represent problems by focusing on irrelevant features. The issue of knowledge representation was studied in a number of domains such as chess (e.g. Chase and Simon, 1973), physics (Bransford et al 1989; Chi, Feltovich and Glasser 1981; Schiano et al 1989;), medicine (Patel and Groen, 1991), and computer sciences (Davies et al 1995). Findings showed that experts tend to encode and represent information through more extensive and significant domain knowledge than novices, affecting the retrieval of qualitative and relevant information in the solution of the problem.

\subsection{Experts and novices: the use of analogy}

The level of expertise was observed to have an effect on the use of analogy (e.g., Collins and Burstein 1989; Goldman 1982; Vosniadou 1989). Daehler et al (1993) claimed that this is partly due to the way that subjects represent knowledge. Experience in a certain domain allows the generation of abstract problem representations, and enhances the probability of structural mappings from source to target. Difficulties in the spontaneous access and use of analogy were reported to be associated with the level of expertise in several studies (Gick and Holyoak 1980; Needham and Begg 1981; Phye 1989). Accordingly, novices often fail to recognize how new problems can be viewed in terms of old problems, and are believed to lack sufficient skills to benefit from explicit instructions to use analogy. Novic (1988) claimed that while experts tend to establish successful analogies that are based on structural similarities, novices tend to retrieve surface features from available sources, which in most cases 
lead to unsuccessful analogies. But if the source shares structural similarities with the problem, then experts are more likely to use the analogy more spontaneously than novices. Ross and Kennedy (1990), on the other hand, demonstrated that surface features offer a means by which novices can establish relationships between problems of a particular type, and form generalizations of that type of problem. Blessing and Ross (1996) investigated how experienced problem solvers utilize surface features while solving problems. Through a series of experiments, these theorists showed that important correlations exist between problems with similar deep structures and their surface features. They claimed that although experts often focus on a problem's deep structure, they also utilize surface features to access a source problem. Relying on surface features to access a source problem may be considered a helpful heuristic that can lead to the establishment of a successful analogy.

\section{Empirical Research}

The use of visual analogies by novice and expert designers during the design process was addressed through empirical research.

\subsection{Objectives and Hypotheses}

We have claimed that most references to the design literature on the use of analogy are anecdotal. Consequently, one of the objectives of this work was to provide empirical evidence of the use of visual analogy in design problem solving. The main objective of the empirical research was to analyze whether novice, as compared to expert designers, use visual analogical reasoning to solve design problems, and how they go about doing so during the design process.

According to Johnson-Laird (1989), the degree of complexity in accessing an analogy is, to a large extent, dependent on how remote or close the distance between target and source is. Considering that within-domain analogies are easier to access, our first hypothesis was that novices would tend to identify and retrieve analogical principles from visual displays belonging to the same domain of the problem (within-domain sources). In contrast, experts would tend to do the same from visual displays belonging to a remote domain (between-domain sources). Our second hypothesis had to do with expertise and the use of analogy. Researchers such as Gentner (1989), Holyaok and Thagard (1989), and Keane (1988) have claimed that while novices tend to establish surface analogies, which are based on accessible features of the sources, experts are able to establish structural analogies, which generally lead to successful results. In the second hypothesis it was proposed that novices, in contrast to experts, are incapable of establishing deep analogies between the provided visual sources and the target problem. It was conjectured that architects, in contrast to novices, benefit from specific instructions to reason by analogy.

Problem understanding is a crucial part of design problem solving. Designers have to tackle problems that are ill-defined, not sufficiently specific, and include significant, implicit constraints (Simon 1981). Design 
is to some extent directed by the constraints imposed on the problem. It is quite frequent that in order to solve a design problem designers activate a large number of constraints. The addition of constraints can be guided by established principles and guidelines, individual preferences, or by cognitive strategies such as analogy (Eckersley et al 1999). While elaborating their understanding of a problem, experts dedicate a substantially greater effort than novices. They try to gather all the available constraints imposed on the design, which help to reduce the range of possible design solutions to be explored. In our research, we wanted to test the effect of the use of visual analogy with respect to constraint generation, and the production of alternative solutions in both groups of subjects. We hypothesized that experts, contrary to novices, will add new constraints to the problem at hand, but will create a small number of alternative solutions.

\subsection{Subjects}

Twenty-six architectural designers participated in the experiment carried out in this research. The first group of subjects included eleven architects with a minimum of seven years of experience. The second group was composed of fifteen advanced architecture students, from the third, fourth or fifth year of undergraduate studies.

\subsection{Experiment}

Subjects were assigned a design problem, and provided with a board on which a collection of visual displays was presented. They were informed that some of the pictorial material available to them could be considered as potential sources for analogy. The display included 12 within-domain images from the architectural domain, as well as 12 between-domain images from remote domains.

Subjects were asked to identify relevant visual sources, and to use analogy to solve the assigned design problem. Results obtained from the group of novices were compared with those obtained from the group of experts.

The three different design problems solved in the experiment consisted of: (i) the prison; (ii) the viewing-terrace; and (iii) the dwellings. The first problem was concerned with the design of a single-story prison containing facilities for prisoners and for guards, and a total of 80 cells. Each cell should have one of its sides facing the exterior. The design must allow for an effective control over prisoners. The second problem consisted in designing a 30 square meter viewing-terrace at the top of a 16-meter high precipice. The terrace had to be divided in two parts: while one part should have maximum contact with the ground, the other should have minimum contact with the ground. The third problem was to design and organize a set of 20 small, repetitive, and compact dwelling units arranged in a way that minimizes exposure to the exterior. The design layout of the dwellings had to comply with orthogonal geometry, and be restricted to a single floor. 


\subsection{Procedure}

The experiments were conducted in a research laboratory, or at the architect's offices, in individual design sessions. Subjects were given approximately twenty minutes to solve the design problem. They were requested to verbalize their thoughts, as the design session was videotaped. The recorded verbalizations and sketches were used to analyze the protocols produced in each design session. Before commencing the design task, subjects were allowed to present the experimenter with questions. The experimenter did not intervene during the rest of the experiment.

Since in some cases subjects solved two design problems, the number of statistical 'entries' exceeded the number of subjects. All in all, the number of problems solved by the group of experts was 18, and the number of problems solved by the group of novices was 24 .

\subsection{Assessment}

In order to test the impact of the level of expertise while reasoning by analogy, a number of dependent variables were analyzed from the protocols produced by subjects during each design session. These consisted of: identification of visual displays, retrieval of visual displays, use of analogical principles, addition of constraints, and production of alternative design solutions.

1 Identification of visual displays: each visual display identified by the subject from the provided set of images was marked with a value of 1 point, and classified according to identified within-domain and betweendomain categories. For example, while looking at alternative visual displays, the subject commented: "I see the image of the atom and electrons, the tree, ..." (See Figs. 1b, and 1c), "and I also visualize the image of the church..." (See Fig. 1a). As a result, 2 points were assigned to the 'identified between-domain displays' category, and 1 point was assigned to the 'identified within-domain displays' category.

2 Retrieval of visual displays: the visual displays that were considered as analogical sources were marked with a value of 1 point, and classified according to retrieved within-domain, or between-domain categories. For example, when the subject said: "I think that the image of the bottles can be of some help to organize the cells..." (See Fig. 1g) 1 point was assigned to the 'retrieved between-domain displays' category, and 0 point to the 'retrieved within-domain displays' category.

3 Use of analogical principles: if subjects managed to successfully solve the design problem, they were considered to have used a deep analogy. In contrast, if they failed to arrive at a successful solution, they were thought to have established a surface analogy. Three naïve judges, who possess at least 7 years of professional experience in the field of architecture, scored the quality of the designs. In order to do so, an ordinal scale from 1 (minimum) to 5 (maximum) points was assigned. Since there is no clear cut definition that distinguishes between successful 
and unsuccessful solutions, in one comparison between groups of subjects, solutions were considered successful when assigned more than 3 points, and in another comparison more than 4 points.

4 Addition of constraints: a value of 1 point was assigned when subjects considered more constraints than those originally required in the design problem, and a value of 0 points when no additional constraints were included in the problem. For example, if the subject said: "I would like to add a playground area to the dwellings problem" 1 point was assigned to the 'constraint addition' category (for an example, see section 4.2).

5 Provision of alternative design solutions: a value of 1 point was assigned when subjects proposed more than one design solution, and a value of 0 points was assigned for those subjects that proposed only one solution.

\subsection{Statistical Analysis Methods}

Data obtained from the experiments was submitted to a T-Test, and a Chi-Square Test for statistical analyses. For statistical analysis purposes, the three design problems ("the Prison", "the Dwellings", and "the Viewing-Terrace") were grouped together in each group of subjects.

\section{Qualitative results: Novices and experts solving design problems aided by analogy}

In this section, we illustrate two individual design problem-solving sessions, one each of a novice and an expert designer, in which visual analogy was to be used. In the first case, we show an example of an unsuccessful attempt at problem solving in which a student did not manage to use visual analogy to solve a design problem. In the second case, we describe an example in which an experienced architect successfully used visual analogy. Both subjects were required to solve the dwelling problem.

\subsection{Unsuccessful attempt at design problem solving by a novice}

The subject that participated in this experiment was a student who started by scrutinizing the visual displays, and identified a within-domain image the plan of a church illustrated in Figure 1a. While inspecting this picture, she tried to see how it could help satisfy the design requirement of 'compact organization of the cells'. She commented:

"The [visual display belonging to the] plan of the church is an example of a compact organization of a number of similar cells... Anyway, the external perimeter is quite large... This is because [the units] are arranged according to a linear organization that is exposed to this [internal] side, and also to this [external] side..."

Subsequently, the subject attempted to establish a correspondence with the design problem, and produced a sketch, which is presented as Figure 2. However, instead of abstracting the visual source so as to establish a 
structural analogy with the problem, she reproduced a copy of the image of the church plan.

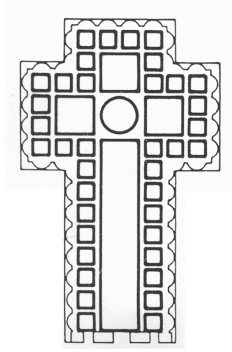

(a)

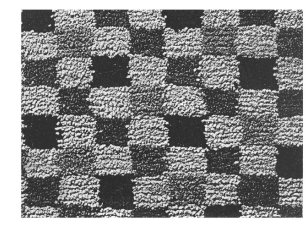

(e)

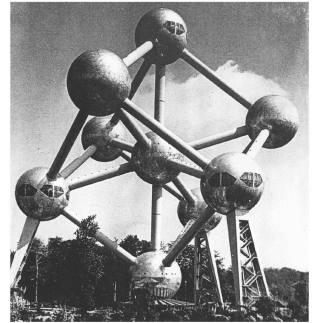

(b)

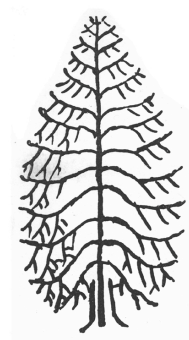

(c)

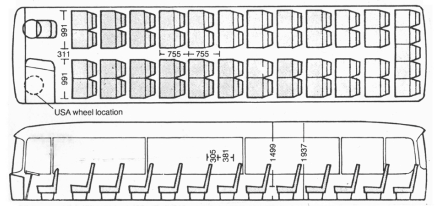

(d)

Figure 1 - Displays considered during the solving of the 'Dwelling' problem. a) Plan of a church; b) Atom and electrons; c) Tree; d) Plan of a bus; e) Textile fabric; f) Typewriter; g) Line of bottles

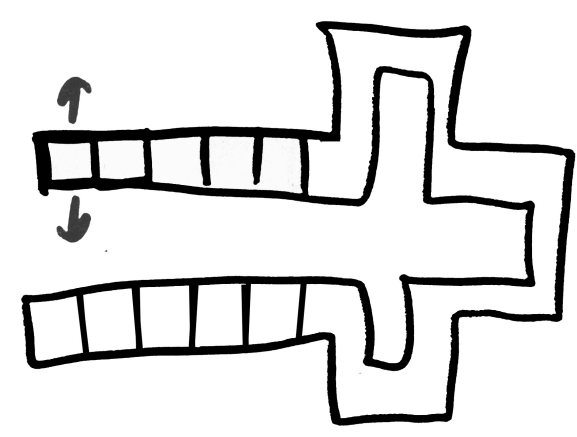

The subject was not satisfied with her plan, and decided not to further refine it. She continued observing the visual displays provided, and discovered a between-domain source representing a construction of an atom and the revolving electrons, as demonstrated in Figure $1 \mathrm{~b}$.

Figure 2 - First sketch produced by the novice designer

However, while exploring this visual display the student focused on surface features such as the connection between the atom and the electrons, or the three-dimensional organization of the schema:

"In the visual display about that sort of structure, there are balls that are related one with the other through connectors... the organization [of the schema] is three-dimensional but not linear..."

In order to try to establish correspondences between visual source and target, the novice designer made a second sketch, in which she reproduced a copy of the atom model, as displayed in Figure 3. However, 
she was unable to abstract it further, and therefore failed to retrieve a structural principle and establish an analogy with the problem.

"In principle, this kind of organization deals with the principle of compact organization, but the connections between the units are more problematic... I cannot see anything else..."

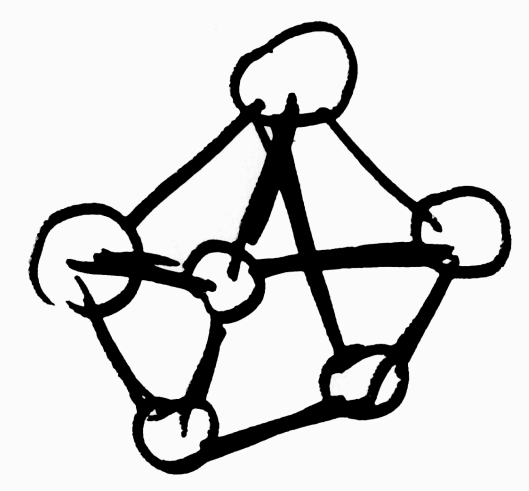

Her attempts to discover a potential analogical source continued: she focused on a between-domain image of a tree, depicted in Figure 1c. However, again, she retrieved surface aspects such as the idea of cluster organization that did not help her find a successful organization principle that can meet the design requirements. Her result is presented in Figure 4 below.

Figure 3 - Second sketch produced by the novice designer

"Perhaps I can consider the principle of the tree...where the organization seems to be very effective...probably I should consider a cluster organization of units like these..."

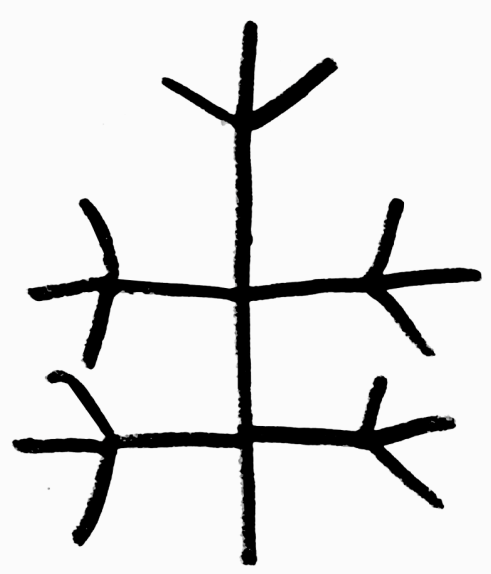

Her last proposed design schema did not answer to the requirements of minimum exposure to the exterior. Her lack of expertise played a role in her inability to represent an abstraction from the visual sources, and establish a deep analogy with the target (Marchant et al 1993). Instead, she reproduced almost exact copies of the sources provided, and focused on surface properties, which did not lead to successful solutions.

Figure 4 - Third sketch produced by the novice designer

\subsection{Successful design problem solving by an expert}

The architect began the design session by scanning almost exclusively between-domain visual images. These were selected because they shared one common principle: all of them embraced the concept of repetitiveness. The visual displays he referred to are illustrated in Figure 1:

"Now I have to look for a common principle that can help me solve the design problem...there is certainly a repetitiveness [principle] in most of [the visual displays] that make them work... and... repetitiveness, it would seem 
to me that this is the common principle. The repetitiveness of the typewriter, ...just the lining of the bottles, in all the rest there is a kind of repetitiveness, on the chapel... the church... repetitiveness of the seats in the bus, ...the repetitiveness of the fabric... that is the constant, the repetition of the branches of the tree..."

The architect succeeded in establishing a structural correspondence between the visual sources and the problem at hand, and started sketching. His first sketch, illustrated in Figure 5, appeared to be influenced by the structural principle of 'repetitiveness' embraced in the visual displays identified.

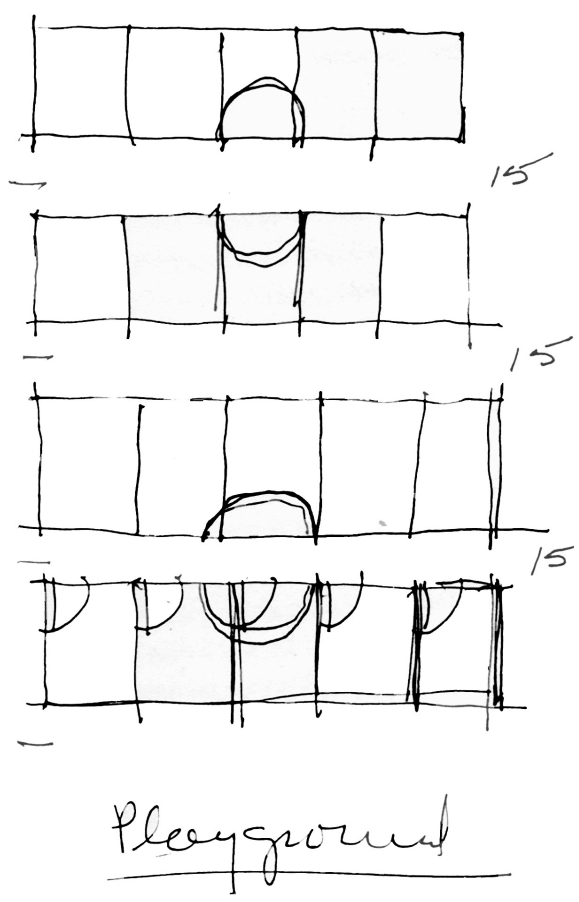

While making his first sketch, the experienced designer managed to activate his memory, and retrieve knowledge related to the row house organization, a typological dwelling that embrace the structural principle of 'density' and 'compactness' between the units. In reference to the activation memory phenomena, Anderson (1983) provided a theory based on search mechanisms. His information processing approach focused on the notion of semantic networks, which is related to the principle of symbolic association in memory. In the case of the architect, his associative structures allowed him to retrieve a design principle

Figure 5 - First sketch produced by the expert designer

from a within-domain display that helped answer to the design requirement dealing with the 'compact organization of the cells'. He commented:

"Obviously there are other ways of creating the twenty apartments, even in an urban setting, but I don't think that anything can be as dense as the row house".

Vosniadou (1989) argued that a within-domain analogy could be established between a source and a problem if it embraces the transference of an explanatory structure. She added that belonging to the same or a different domain is not a defining characteristic of the quality of an analogy. The defining characteristic of analogical reasoning is similarity in underlying structure. Thus, structural similarity can be established between objects that belong to different conceptual domains as well as between objects that belong to similar domains. In the current example, we considered that the analogical principle the subject retrieved from memory, although belonging to a within-domain display such as dwelling, 
embraced an explanatory structure that helped him to successfully solve the design problem.

While designing the tight dwelling organization, the subject decided to add further constraints that those that were required in the original goals, such as a couple of streets, and a shared playground. Afterwards, he made a second sketch, in which he developed a prototypical dwelling unity, with its internal functional organization, as illustrated in Figure 6.

"There are five compact apartments in each block... These should be two main streets. Perhaps it can be added a shared playground... Well the flat should be 25 square meters...it seems to be that it has to be so tight and compact. Maybe this ... can be an example of a prototypical flat."

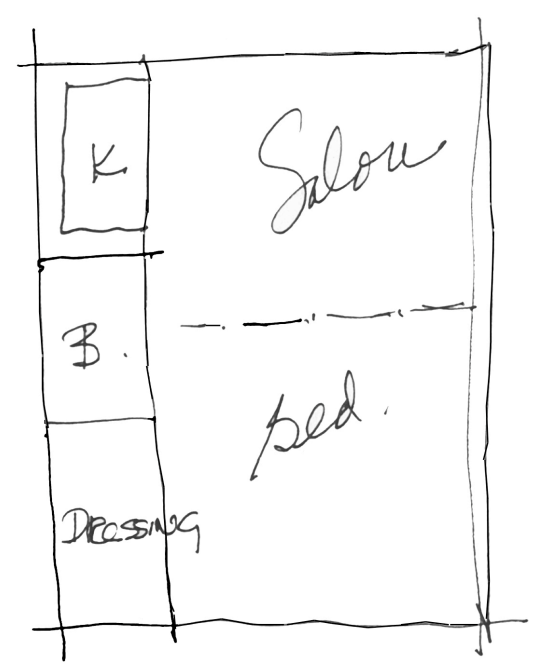

The designer was able to organize the twenty dwelling units according to four compact blocks of five repetitive apartments each, and to further refine one of them. The experiment ended with a successful outcome that fully met the design requirements.

Figure 6 - Second sketch produced by the expert designer

\section{Quantitative results}

The prediction that novices will identify and retrieve analogs from displays belonging to the same domain of the design problem was not confirmed. Results showed that the number of between-domain visual displays that this group of subjects focused on was significantly larger than that of within-domain displays, as presented in Table $1 \quad(t=-4.813 ; d f=23$; $\mathrm{p}<.001)$. On the other hand, no significant differences between both kinds of visual displays were found in the retrieval process, as displayed in Table 2. Novices were able to retrieve analogical principles from betweendomain as much as from within-domain visual displays $\left(\square^{2}=.505 ; \mathrm{df}=1\right.$; $p \sim 0.477$ ).

Table 1- Identified visual displays by novices

\begin{tabular}{|c|c|c|c|}
\hline Visual source & Mean & $\begin{array}{c}\text { Std. } \\
\text { Deviation }\end{array}$ & $\begin{array}{c}\text { Std. Error } \\
\text { Mean }\end{array}$ \\
\hline $\begin{array}{c}\text { Within-domain } \\
\text { displays }\end{array}$ & 1.79 & 1.06 & .216 \\
\cline { 1 - 2 } $\begin{array}{c}\text { Between-domain } \\
\text { displays }\end{array}$ & 4.62 & 2.42 & .495 \\
\hline
\end{tabular}


Visual Analogy as a Cognitive Strategy in the Design Process: Expert Versus Novice Performance

Table 2 - Retrieved visual displays by novices

\begin{tabular}{|c|c|c|c|c|}
\hline \multicolumn{2}{|c|}{} & \multicolumn{2}{|c|}{$\begin{array}{c}\text { Retrieved between-domain } \\
\text { displays }\end{array}$} & \multirow{2}{*}{ Total (\%) } \\
\cline { 2 - 3 } \multicolumn{2}{|c|}{} & No (\%) & Yes (\%) & \\
\hline \multirow{2}{*}{$\begin{array}{c}\text { Retrieved } \\
\text { within- } \\
\begin{array}{c}\text { domain } \\
\text { displays }\end{array}\end{array}$} & $\begin{array}{c}\text { No } \\
(\%)\end{array}$ & 4.2 & 16.7 & 20.8 \\
\cline { 2 - 2 } & $\begin{array}{c}\text { Yes } \\
(\%)\end{array}$ & 29.2 & 50.0 & 79.2 \\
\cline { 1 - 1 } \multicolumn{2}{|c|}{ Total } & 33.3 & 66.7 & 100 \\
\hline
\end{tabular}

The prediction that experts will identify and retrieve analogs from visual displays belonging to a different domain of the design problem was fully confirmed. Results obtained from this group revealed a significant difference in the use of between-domain displays over within-domain displays $(\mathrm{t}=-3.108 ; \mathrm{df}=16 ; \mathrm{p}<.007)$ in the identification process, and $\left(\square^{2}=3.58 ; \mathrm{df}=1 ; \mathrm{p}<.058\right)$ in the retrieval process, as demonstrated in Tables 3 and 4.

Table 3 - Identified visual displays by experts

\begin{tabular}{|c|c|c|c|}
\hline Visual source & Mean & $\begin{array}{c}\text { Std. } \\
\text { Deviation }\end{array}$ & $\begin{array}{c}\text { Std. Error } \\
\text { Mean }\end{array}$ \\
\hline $\begin{array}{c}\text { Within-domain } \\
\text { displays }\end{array}$ & 2.88 & 1.90 & .460 \\
\cline { 1 - 1 } $\begin{array}{c}\text { Between-domain } \\
\text { displays }\end{array}$ & 5.23 & 2.99 & .725 \\
\hline
\end{tabular}

Table 4 - Retrieved visual displays by experts

\begin{tabular}{|c|c|c|c|c|}
\hline \multicolumn{2}{|c|}{} & \multicolumn{2}{|c|}{$\begin{array}{c}\text { Retrieved between-domain } \\
\text { displays }\end{array}$} & \multirow{2}{*}{ Total (\%) } \\
\cline { 2 - 4 } \multicolumn{2}{|c|}{} & No (\%) & Yes (\%) & \\
\hline \multirow{2}{*}{$\begin{array}{c}\text { Retrieved } \\
\text { within- } \\
\begin{array}{c}\text { domain } \\
\text { displays }\end{array}\end{array}$} & $\begin{array}{c}\text { No } \\
(\%)\end{array}$ & 11.1 & 61.1 & 72.2 \\
\cline { 2 - 2 } & $\begin{array}{c}\text { Yes } \\
(\%)\end{array}$ & 16.7 & 11.1 & 27.8 \\
\cline { 1 - 1 } \multicolumn{2}{|c|}{ Total } & 27.8 & 72.2 & 100 \\
\hline
\end{tabular}

The prediction that novices in contrast to experts will not be able to establish successful analogies from the provided visual sources was not confirmed. Both novices and experts managed to establish deep analogies in almost every observed case. Results showed that no statistical differences exist between both groups of subjects. As indicated in Table 5, for a comparison between successful design solutions of novices and experts that scored 3 points or more, we found ( $\square 2=.120 ; d f=1 ; p \sim 729)$. Similar results were found for a comparison between successful solutions of novices and experts that scored over 4 points $(\square 2=.389 ; \mathrm{df}=1$; p 0.533) (Table 6). 
Table 5 - Establishing successful analogy between visual sources and the design target (Solutions scoring 3 or more points).

\begin{tabular}{|c|c|c|c|}
\hline & \multicolumn{2}{|c|}{ Successful use of visual analogy } & \multirow{2}{*}{ Total (\%) } \\
\cline { 2 - 3 } & No (\%) & Yes (\%) & \\
\hline $\begin{array}{c}\text { Expert } \\
\text { designers }\end{array}$ & 5.6 & 94.4 & 100 \\
\cline { 1 - 1 } $\begin{array}{c}\text { Novice } \\
\text { designers }\end{array}$ & 8.3 & 91.7 & 100 \\
\hline
\end{tabular}

Table 6 - Establishing successful analogy between visual sources and the design target (Solutions scoring over 4 points).

\begin{tabular}{|c|c|c|c|}
\hline & \multicolumn{2}{|c|}{ Successful use of visual analogy } & \multirow{2}{*}{ Total (\%) } \\
\cline { 2 - 3 } & No (\%) & Yes (\%) & \\
\hline $\begin{array}{c}\text { Expert } \\
\text { designers }\end{array}$ & 44.4 & 55.5 & 100 \\
\hline $\begin{array}{c}\text { Novice } \\
\text { designers }\end{array}$ & 54.1 & 45.9 & 100 \\
\hline
\end{tabular}

The prediction that experts, in contrast to novices, will add new constraints to the design, and will produce a small number of alternative solutions was completely confirmed. A significant difference was observed between the groups regarding the 'addition of new constraints'. Results, as presented in Table 7 , showed that the group of experts surpassed the group of novices $\left(\square^{2}=8.84 ; \mathrm{df}=1 ; \mathrm{p}<.003\right)$. Moreover, as shown in Table 8, experts, in contrast to novices, generated a significantly smaller number of alternative design solutions $\left(\square^{2}=5.56 ; \mathrm{df}=1 ; \mathrm{p}<.018\right)$.

Table 7 - Addition of new constraints to the design problem

\begin{tabular}{|c|c|c|c|}
\hline & \multicolumn{2}{|c|}{ Addition of constraints } & \multirow{2}{*}{ Total (\%) } \\
\cline { 2 - 3 } & No (\%) & Yes (\%) & \\
\hline $\begin{array}{c}\text { Expert } \\
\text { designers }\end{array}$ & 38.9 & 61.1 & 100 \\
\cline { 1 - 1 } $\begin{array}{c}\text { Novice } \\
\text { designers }\end{array}$ & 83.3 & 16.7 & 100 \\
\hline
\end{tabular}

Table 8 - Provision of alternative design solutions

\begin{tabular}{|c|c|c|c|}
\hline & \multicolumn{2}{|c|}{ Alternative design solutions } & \multirow{2}{*}{ Total (\%) } \\
\cline { 2 - 3 } & No (\%) & Yes (\%) & \\
\hline $\begin{array}{c}\text { Expert } \\
\text { designers }\end{array}$ & 61.1 & 38.9 & 100 \\
\hline $\begin{array}{c}\text { Novice } \\
\text { designers }\end{array}$ & 25.0 & 75.0 & 100 \\
\hline
\end{tabular}

\section{Discussion and Conclusions}

Results obtained from the experiments validated the hypothesis that experts will identify and retrieve analogs from visual displays belonging to 
a different domain of the design problem. However, the hypothesis that novices will identify and retrieve analogs from displays belonging to the same domain of the design problem was not validated. The finding that both groups of subjects identified between-domain displays is particularly remarkably for novices who, contrary to our predictions, were able to focus on a large number of between-domain displays. According to Dejong (1989) between-domain displays contain structural commonalities, which are supposed to lead to successful analogies, but are more difficult to access. It was also observed that experts were likely to retrieve a large number of between-domain visual displays. We postulate that due to their strong, and well-organized structures of knowledge (e.g., Gero 2002) within-domain displays played an irrelevant role in their design process. Novices, however, were able to retrieve analogs from between-domain as often as from within-domain displays. The large, detailed, and heterogeneous collection of graphic material provided in the experiment might had a positive effect to overcome difficulties in the access of between-domain displays.

The hypothesis that novices in contrast to experts will not be able to establish successful analogies from the provided visual sources was not confirmed. It was observed that both groups of subjects were able to retrieve deep principles from the available visual sources, and create successful analogies. These findings contrast with Gick and Holyoak (1980), Novick (1988), and Phye (1989) who claimed that novices often have difficulties to spontaneously access, and use relevant analogies. We propose that instructions to use analogy, together with the large collection of within- and between-domain visual displays made available to subjects played a role in this.

The hypothesis that experts, in contrast to novices, will add new constraints to the design, and will create a small number of alternative solutions was fully confirmed. In the group of novices, it was verified that the availability of visual sources did not have an effect in the addition of further constraints to the problem at hand. Their solutions tended to be schematic, characterized by a low level of detail. However, the use of visual analogy helped novices to expand their explorations in the 'problem space' (Newell and Simon 1972), and enhance the generation of different solutions. On the other hand, we found that although experts added constraints to the original problem, they did not produce alternative design solutions. Experienced architects, who have developed knowledge structures, were able to direct their search efforts to fertile metaphorical 'problem spaces' where successful solutions could potentially be found. These findings correspond with Eckersley et al (1999), and with the study carried out on differences in expertise between chess players (Chase and Simon 1973). In the above study, it was observed that while struggling to find an appropriate solution, novice players conducted an exhaustive search through both relevant and irrelevant knowledge embraced in the 'problem space'. Master players, however, demonstrated their awareness of those narrow sectors in which their exploratory efforts would potentially lead to more promising outcomes. 
Results derived from this study have important implications on design education, and on the development of design skills. It is believed that in the architectural design studio, training novice students in the use of within-domain, and between-domain visual sources in particular, can significantly contribute gaining an insight on how analogical reasoning can be spontaneously identified, retrieved, and applied in specific design tasks.

\section{Acknowledgements}

This work is a continuation of Hernan Casakin's D.Sc. thesis on The Use of Visual Analogy in Design, supervised by Prof. Gabriela Goldschmidt. Thanks are due to Dr. Itzhak Benenson, Ran Goldblatt, Michael Winograd, and Erez Hatna for their helpful assistance.

\section{References}

Anderson, J. (1983) A spreading activation theory of memory, Journal of Verbal Learning and Verbal Behavior, 22, pp 261-295.

Akin, O. (1990) Necessary conditions for design expertise and creativity, Design Studies, 7 (2), pp 107-113.

Beveridge, M. and Parkins, E. (1987) Visual representation in analogical problemsolving, Memory and Cognition, 15(3), pp 230-237.

Bransford, J., Franks, J., Vye, N. and Sherwood, R. (1989) New approaches to instruction: because wisdom can't be told in Vosniadou, S. and Ortony, A. (eds) Similarity and analogical reasoning, pp 470-497, Cambridge University Press, Cambridge.

Casakin, H. and Goldschmidt, G. (1999) Expertise and the Use of Analogy and Visual Displays: Implications for Design Education, Design Studies, 20 (2), pp 153-175.

Casakin, H. and Goldschmidt, G. (2000) Reasoning by Visual Analogy in Design Problem-Solving: The Role of Guidance, Environment and Planning B: Planning and Design, 27, pp 105-119.

Casakin, H. (2002) Well-Defined vs. Ill-Defined Design Problem Solving: The Use of Visual Analogy, in Common Ground Proceedings of The Design Research Society International, Stoke on Trent, pp 202-216.

Collins, A. and Burstein, M. (1989) After word: A framework for a theory of comparison and mapping, in Vosniadou, S. and Ortony, A. (eds). Similarity and analogical reasoning, pp 546-565, Cambridge University Press, Cambridge.

Chase, W. G. and Simon, H. A. (1973) Perception in chess, Cognitive Psychology, 4, pp 55-81.

Chi, M. T. H., Feltovich, P. J. and Glasser, R. (1981) Categorization and representation of physics problems by experts and novices, Cognitive Science, 5, pp 121-152.

Daheler, M. and Chen, Z. (1993) Protagonist, theme, and goal object: effects of surface features on analogical transfer, Cognitive Development, B (2), pp 211229. 
Davies, S. P., Gilmore, D. J. and Green, T. R. (1995) Are objects that important? Effects of expertise and familiarity on classification of object-oriented code, Human-Computer Interaction,10, pp 227-248.

Dejong, G. (1989). The role of explanation in analogy; or, the curse of an alluring name, in Vosniadou, S. and A. Ortony, (eds.). Similarity and analogical reasoning, 346-365. Cambridge: Cambridge University Press.

Dominowski, R. (1995). Productive Problem Solving, in R. Finke, T. Ward, and S. Smith (1995). The creative cognition approach, 73-95. Cambridge, MA : MIT Press.

Eckert, C., Stacey, M. and Wiley, J (1999). Expertise and designer burnout. International conference on engineering design, ICED, Munich.

Glaser, R. (1989) Expertise and Learning: How do we think about instructional processes now that we have discovered knowledge structures?, in D Klahr \& $\mathrm{K}$ Kotovsky (eds) Complex information processing: the impact of Herbert A Simon, pp 269-282, Erlbaum, Hillsdale, NJ.

Gentner, D. (1983) Structure-mapping: a theoretical framework for analogy, Cognitive Science, 7, pp 155-170.

Gero, J. and Maher, M. L. (1993) Modeling creativity and knowledge-based creative design, in Gero, J. and Maher. M. L. (eds), pp 1-7, Lawrence Erlbaum Associates, Hillsdale, NJ.

Gero, J. and Kavakly, M. (2002) Strategic knowledge differences between an expert and a novice, in Pre-proceedings of Human behavior in design, Schloss Hohenkammer, no pp number.

Gick, M. and Holyoak, K. (1980) Analogical problem-solving, Cognitive Psychology, 12, pp 306-355.

Goldman, S., Pellegrino, J., Parseghian, P. and Sallis, R. (1982) Developmental and individual differences in verbal analogical reasoning, Society for Research in Child Development, 53, pp 550-559.

Goldschmidt, G. (1994). Visual analogy in design, in Trappl, R. (ed) Cybernetics and Systems '94, pp 507-514, World Scientific, Singapore.

Goldschmidt, G. (1995) Visual displays for design: imagery, analogy and databases of visual images, in Koutamanis, A., Timmermans, H. and Vermeulen, I. (eds) Visual databases in architecture, pp 53-74, Aldershot, Avebury.

Goldschmidt, G. (1999) Visual analogy: a strategy for design reasoning and learning, in Eastman, C., McCracken, W. and Newstetter, W. (eds) Design knowing and learning: cognition in design education, pp 199-219, Elsevier, New York.

Holyoak, K. (1990) Problem-solving, in Osherson D.N. and Smith E.E. (eds) Thinking: An invitation to cognitive science, vol 3, pp 117-146. MIT Press, Cambridge, MA

Johnson-Laird, P. (1989) Analogy and the exercise of creativity, in Vosniadou, S. and Ortony, A. (eds) Similarity and analogical reasoning, pp 313-331, Cambridge University Press, Cambridge 
Marchant, G., Robinson, J., Anderson, U. and Schadewald, M. (1993) The use of analogy in legal argument: problem similarity, precedent and expertise, Organizational Behaviour and Human Decision Processes, 55, pp 95-119.

Medin, D. and Ross, B. (1990) Cognitive psychology, Harcourt Brace Pub, NY.

Needham, D. and Begg, I. (1991) Problem-oriented training promotes spontaneous analogical transfer: memory-oriented training promotes memory for training, Memory and Cognition, 19 (6), pp 543-557.

Newell, A. and Simon, H. (1972) Human problem-solving, Englewood Cliffs, Prentice Hall, NJ.

Novick, L. (1988) Analogical transfer, problem similarity, and expertise, Journal of Experimental Psychology: Learning, Memory, and Cognition, 14(3), pp 510-520.

Novick, L. and Holyoak, K. (1991) Mathematical problem-solving by analogy, Journal of Experimental Psychology: Learning, Memory, and Cognition, 17(3), pp 398-415.

Patel, V. L. and Groen G J. (1991) The general and specific nature of medical expertise: a critical look, in Ericsson, K. A., Smith, J. (eds) Studies of Expertise: Prospects and limits, Cambridge University Press, Cambridge, MA.

Phye, G. (1989) Schemata training and transfer of an intellectual skill, Journal of Education Psychology, 81 (3), pp 347-352.

Schiano, D., Cooper, Glaser, R. and Zhang, H. (1989) Highs are to lows as experts are to novices: Individual differences in the representation and solution of standardized figural analogies, Human Performance, 2 (4), pp 225-248.

Simon, H.A. (1981) The Sciences of the Artificial, MIT Press, Cambridge MA, 2nd ed.

Sternberg, R. and Ketron, J. (1982) Selection and implementation of strategies in reasoning by analogy, Journal of Educational Psychology, 74, (3), pp 399-413.

Verstijnen, I., Wagemans, A., Heylighen, A., and Neuckermans, H. (1999) Sketching, Visual Analogies and Domain-Expertise, in Proceedings of $4^{\text {th }}$ Design Thinking Research Symposium: Design Representation, 77, Cambridge, MA, pp II.71-II.

Vosniadou, S. (1989) Analogical reasoning as a mechanism in knowledge acquisition: a developmental perspective, in Vosniadou, S. and Ortony, A. (eds) Similarity and analogical reasoning, pp 413-437. Cambridge University Press, Cambridge.

Vosniadou, S. and Ortony, A. (1989) Similarity and analogical reasoning: A synthesis, in Vosniadou, S. and Ortony, A. (eds) Similarity and analogical reasoning, pp 1-17, Cambridge University Press, Cambridge.

Weisberg, R. and Alba, J. (1982) Problem solving is not like perception: more on Gestalt theory, Journal of Experimental Psychology 111 (3), pp 326-330.

Wertheimer, M. (1959/1982) Productive thinking, Harper \& Row, NY. 